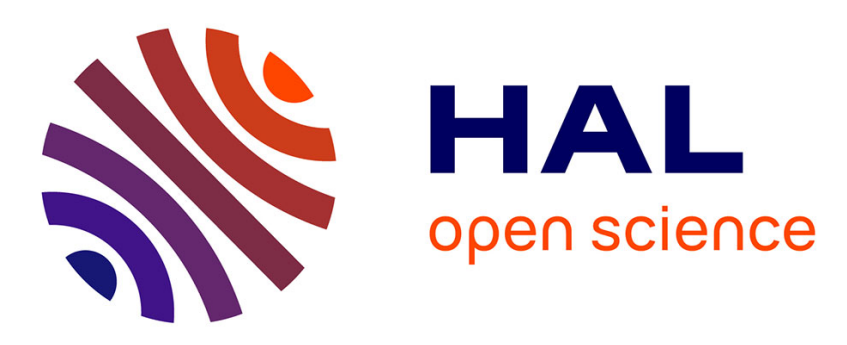

\title{
Implementation of the Standardized Human Body Communications - A Feasibility Study
}

R. Vauche, H. Bounaceur, S. Zerenini, N. Dehaese, Jean Gaubert, Herve Barthelemy, Valentin Gies

\section{- To cite this version:}

R. Vauche, H. Bounaceur, S. Zerenini, N. Dehaese, Jean Gaubert, et al.. Implementation of the Standardized Human Body Communications - A Feasibility Study. 2018 25th IEEE International Conference on Electronics, Circuits and Systems (ICECS), Dec 2018, Bordeaux, France. pp.643-644, 10.1109/ICECS.2018.8618037 . hal-01856908

\section{HAL Id: hal-01856908 https://hal.science/hal-01856908}

Submitted on 6 Jan 2022

HAL is a multi-disciplinary open access archive for the deposit and dissemination of scientific research documents, whether they are published or not. The documents may come from teaching and research institutions in France or abroad, or from public or private research centers.
L'archive ouverte pluridisciplinaire HAL, est destinée au dépôt et à la diffusion de documents scientifiques de niveau recherche, publiés ou non, émanant des établissements d'enseignement et de recherche français ou étrangers, des laboratoires publics ou privés. 


\title{
Implementation of the Standardized Human Body Communications - A Feasibility Study
}

\author{
R. Vauche ${ }^{1}$, H. Bounaceur ${ }^{1}$, S. Zerenini ${ }^{1}$, N. Dehaese ${ }^{1}$, J. Gaubert $^{1}$, H. Barthelemy ${ }^{1}$, V. Gies ${ }^{1}$ \\ ${ }^{1}$ Aix Marseille Univ, Université de Toulon, CNRS, IM2NP, Marseille, France
}

\begin{abstract}
Due to the disparity of the measured human body path losses published in the literature, it is proposed here to make a feasibility study about the implementation of the Human Body Communications (HBC) defined in the IEEE 802.15.6 standard. In this way, the path loss required by the standard is firstly computed. Next, a measurement setup of the human body path loss is presented. Finally, measurement results are compared to the required one and pave the way to studies closer to real use cases.
\end{abstract}

Keywords-Human Body Communications; Capacitive Coupling; Human Body Path Loss

\section{INTRODUCTION}

In 2012, the IEEE 802.15.6 standard [1] dedicated to Wireless Body Area Networks (WBAN) has introduced the specifications of 3 physical layers (PHY): (i) a NarrowBand (NB) PHY specification using the ISM frequency bands, (ii) an Ultra-WideBand (UWB) PHY specification using the $3.1 \mathrm{GHz}$ $10 \mathrm{GHz}$ frequency band, and (iii) a Human Body Communications (HBC) PHY specification using a channel around $21 \mathrm{MHz}$.

On the contrary of standard wireless communications which use for example the air or the vacuum as propagation medium [2], the HBC use the human body as propagation medium and antennas are replaced by electrodes. In this way, HBC can be associated to a particular type of Body Coupled Communications (BCC) which uses the capacitive coupling [3] where only one signal electrode is used on the emitter side and on the receiver side as shown in Fig. 1.

Since HBC have been standardized, lots of simulated or measured values of the human body path loss have been published as shown in Fig. 2 [4]. However, the human body path loss around $21 \mathrm{MHz}$ is at best between $20 \mathrm{~dB}$ and $60 \mathrm{~dB}$ which leads to a high disparity even if a given configuration (coupling type, electrodes position, electrodes type, etc.) is considered. Moreover, it appears that according to the effective value of the human body path loss, the implementation of standardized HBC could be impossible with the specifications (transmitted power, receiver sensitivity, bit rate) defined in the IEEE 802.15.6 standard.

From this analysis, it is proposed in this paper to review the situation by computing in section II the human body path loss required by the HBC PHY specification defined in the IEEE 802.15.6 standard. Next, a setup for human body path loss measurement is proposed in section III. Finally, the measured values of human body path loss are compared to the published ones in section IV and a conclusion on the feasibility of the $\mathrm{HBC}$ implementation is given.

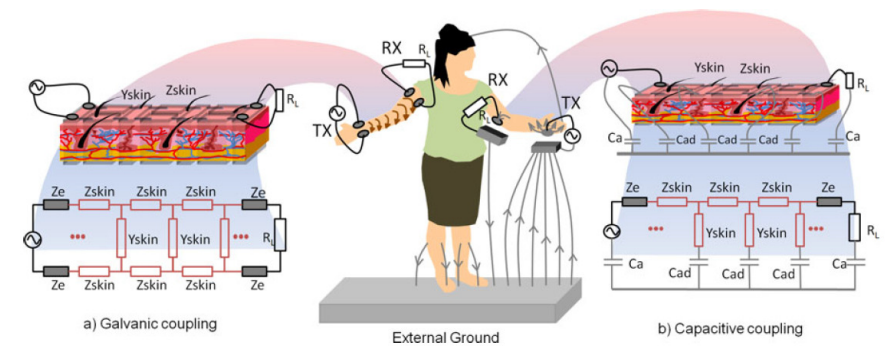

Fig. 1. The two types of body-coupled communications: a) the galvanic coupling, b) the capacitive coupling [3].

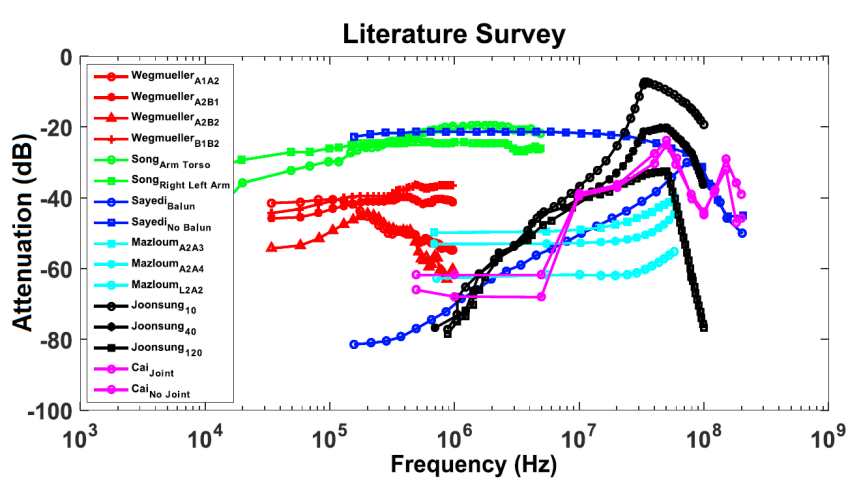

Fig. 2. Attenuation of the human body previously published [4].

\section{COMPUTATION OF THE HUMAN BODY PATH LOSS}

According to the IEEE 802.15.6 standard, the electric field produced by a HBC device shall never exceed $30 \mu \mathrm{V} / \mathrm{m}$ when it is measured at a distance of $30 \mathrm{~m}$ in free space, in addition to be compliant with local regulations. This electric field strength $E$ can be converted in a surface power density $S P D$ with the help of Poynting theorem as follows:

$$
S P D=E \times H=E^{2} / \eta
$$

where $H$ is the magnetic field strength and $\eta$ is the wave impedance of a plane wave in free space which is equal to the square root of the free space permeability-permittivity ratio $(\eta$ can be approximated by $120 \pi$ for air or vacuum). Next, with the help of the Friis formula, it is possible to write the surface power density as a function of the power emitted by the transmitter electrode $P_{T X}$ as follows:

$$
S P D=P_{T X} /\left(4 \times \pi \times d^{2}\right)
$$


where $\mathrm{d}$ is the distance between the transmitter electrode and the electric field probe. From (1) and (2), it is now possible to directly compute the power emitted by the transmitter electrode from the electric field strength as follows:

$$
P_{T X}=4 \times \pi \times d^{2} \times E^{2} / \eta
$$

which gives a maximum emitted power of $27 \mathrm{nW}(-45.7 \mathrm{dBm})$. Finally, it is possible to compute the maximum human body path loss $(\mathrm{dB})$ permitted for $\mathrm{HBC}$ by subtracting the maximum authorized value of $\mathrm{P}_{\mathrm{TX}}(\mathrm{dBm})$ by the minimum receiver sensitivity $(\mathrm{dBm})$ specified by the standard. The minimum receiver sensitivity, the maximum emitted power, and the maximum human body path loss permitted by HBC are summarized in Table I for the different standardized bit rates.

TABLE I. MaXimum Human Body Path LosS Allowed By HBC.

\begin{tabular}{|c|c|c|c|}
\hline $\begin{array}{c}\text { Bit rate } \\
\text { (kbps) }\end{array}$ & $\begin{array}{c}\text { Minimum Receiver } \\
\text { Sensitivity (dBm) }\end{array}$ & $\begin{array}{c}\text { Maximum Emitted } \\
\text { Power (dBm) }\end{array}$ & $\begin{array}{c}\text { Maximum Path } \\
\text { Loss (dB) }\end{array}$ \\
\hline 164.1 & -97.35 & -45.7 & 51.65 \\
\hline 328.1 & -94.34 & -45.7 & 48.64 \\
\hline 656.3 & -91.33 & -45.7 & 45.63 \\
\hline 1312.5 & -88.32 & -45.7 & 42.62 \\
\hline
\end{tabular}

\section{MEASUREMENT OF THE HuMAN BODy PATH LOSS}

To measure the human body path loss, two measurement methods have been in used in the literature. The first one uses a radiofrequency Signal Generator (SG) and a Power Spectrum Analyzer (PSA) [5] whereas the second one uses a Vector Network Analyzer (VNA) [6]. In this paper, the first method using a SG SMBV100A and a PSA FSH4 from Rhode \& Schwarz is considered as shown in Fig. 3. To properly connect the TX \& RX electrodes, SMA cables have been used. Finally, the used test electrodes are dry electrodes for electrical muscle stimulation from Comepa which consist of a $14 \mathrm{~mm}$-diameter disc of silver alloy where the protection sheet has not been removed to avoid oxidization.

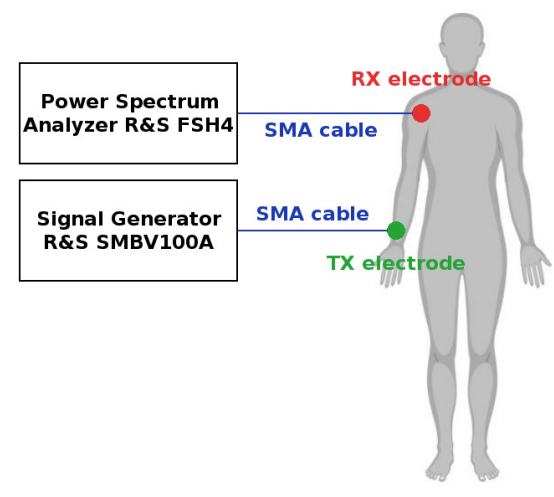

(a)

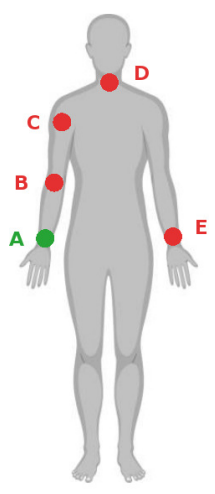

(b)
Fig. 3. Measurment setup of the human body path loss (a), electrodes localizations (b).
The values of the measured human body path loss have been summarized in table II for various electrodes position (averaged on three persons). They have been obtained using a $21 \mathrm{MHz}$ continuous wave with a level of $-46 \mathrm{dBm}$ in order to be compliant with the maximum allowed emitted power. Finally, the PSA has been configured with a span of $10 \mathrm{kHz}$ around $21 \mathrm{MHz}$, a Resolution BandWidth (RBW) of $300 \mathrm{~Hz}$, and an attenuation of $0 \mathrm{~dB}$ to reduce its noise floor to $-100 \mathrm{dBm}$.

TABLE II. MEASURED Human Body Path Loss.

\begin{tabular}{|c|c|c|}
\hline Electrodes position & Range $(\mathbf{c m})$ & Measured Path Loss $(\mathbf{d B})$ \\
\hline A-B & 20 & 32.8 \\
\hline A-C & 40 & 35.8 \\
\hline A-D & 60 & 36.4 \\
\hline A-E & 120 & 37.2 \\
\hline
\end{tabular}

\section{CONCLUSION}

The measured human body path loss obtained with the presented setup is between $32 \mathrm{~dB}$ and $38 \mathrm{~dB}$ according to the electrodes position, which is between the minimum $(20 \mathrm{~dB})$ and the maximum $(60 \mathrm{~dB})$ published in the literature review [4]. It also appears that in these conditions the human body path losses are always lower than the maximum one permitted by the standard which is between $42.62 \mathrm{~dB}$ and $51.65 \mathrm{~dB}$ according to the targeted bit rate. Thus, these measured values of the human body path loss show that standardized HBC can be implemented. However, to confirm this with a configuration closer to a real use case, a basic TX patch, which will generate a $21 \mathrm{MHz}$ continuous wave with a level of $-46 \mathrm{dBm}$, will be designed in addition to a RX patch which will be able to estimate the power received around $21 \mathrm{MHz}$. These patches, which include each one an electrode, will be placed on the skin for different configurations and will make possible the measurement of the human body path loss during motions in order to verify its compatibility with standardized HBC.

\section{REFERENCES}

[1] IEEE 802.15.6-2012 - IEEE Standard for Local and metropolitan area networks - Part 15.6: Wireless Body Area Networks.

[2] C. E. Shannon, "A Mathematical Theory of Communication," The Bell System Technical Journal, vol. 27, pp. 379-423, 623-656, July, Oct. 1948.

[3] M. A. Callejón, D. Naranjo-Hernandez, J. Reina-Tosina and L. M. Roa, "Distributed Circuit Modeling of Galvanic and Capacitive Coupling for Intrabody Communication," in IEEE Transactions on Biomedical Engineering, vol. 59, no. 11, pp. 3263-3269, Nov. 2012.

[4] S. Maity, K. Mojabe and S. Sen, "Characterization of Human Body Forward Path Loss and Variability Effects in Voltage-Mode HBC," in IEEE Microwave and Wireless Components Letters, vol. 28, no. 3, pp. 266-268, March 2018.

[5] J. Bae, H. Cho, K. Song, H. Lee and H. J. Yoo, "The Signal Transmission Mechanism on the Surface of Human Body for Body Channel Communication," in IEEE Transactions on Microwave Theory and Techniques, vol. 60, no. 3, pp. 582-593, March 2012.

[6] M. H. Sayedi, "A novel intrabody communication transceiver for biomedical applications," Ph.D. dissertation, College Eng. Sci., Victoria Univ., Footscray, VIC, Australia, 2014. 